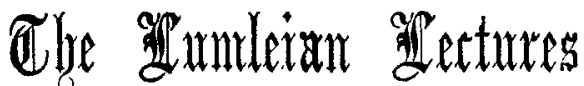

\section{SOME PROBLEMS IN CONNEXION WITH APHASIA AND OTHER SPEECH DEFECTS.}

Delivered before the Royal College of Physicians of London on April 1st, 6th, and 8th, 1897,

By H. CHARLTON BASTIAN, M.A., M.D. LoND., F.R.S.,

CENSOR OF THE COLLEGE; PHYSICIAN TO UNIVERSITY COLLEGE HOSPITAL AND TO THE NATIONAL HOSPITAL FOR THE PARALYBED AND EPILEPTIC.

\section{LEC [URE III. ${ }^{1}$ \\ Delivered on April 8th, 189\%.}

Mr. Phesident and Gentlemen, - At the close of the last lecture I considered the different degrees of amnesia verbalis that may result from functional defects or partial lesions of the left auditory word-centre. We must now consider the effects produced by more serious lesions of this centre.

(b) Effects produced by destruction of the left auditory nord.centre. - Where, instead of partial or mere functional defects, we have to do with more or less complete destruction of the left auditory word-centre by some organic disease a correspondingly complete word-deafness is produced, so that the patient is no longer able to comprehend spoken language. Spoken words become to such a patient mere meaningless sounds. As I have already pointed out, word-blindness (or alexia) is also an occasional consequence of such a lesion, though it is not to be regarded as a necessary accompaniment, whatever Wernicke and Déjerine may say to the contrary. These authorities, moreover, as well as Mirallié, hold that paraphasia is the kind of speech defect that is entailed by destruction of the auditory word-centre. Wyllie also, in his recent work on "The Disorders of Speech," says (p. 289) that the extreme defect in an " auditive" in consequence of this lesion would be what is termed "gibberish aphasia," and adds: "In general, the destruction of the auditory centre leaves the patient in possession of considerable powers of expression." This question as to the nature of the alteration of speech that goes with destruction of the anditory word-centre is a very interesting and important one, and will require careful consideration.

The views that I entertained on this subject some years ago were thus expressed ${ }^{2}$ : "Suppose a person to be suffering from defective activity of the auditory word-centre, so that names cannot be recalled 'voluntarily' or by 'association.' There would already be great hesitation and difficulties in the expression of thoughts both in speech and in writing. But suppose this mere defective activity to be replaced by actual destruction of the left auditory word-centre so that its functional activity became actually lost, words could then, of course, neither be recalled 'voluntarily' nor by 'association,' and, still further, they could not be perceived and consequently could not be imitated. An individual thus affected would neither be able to speak nor to writethat is, he would be completely aphasic, with the superadded peculiarity that he would not readily comprehend spoken and perhaps written language." It should be observed that these statements were made partly as $a$ priori deductions and partly as a result of the observation of actnal cases, though at this period there had only been too few of them. Still, it seemed to me then-and from several points of view would still seem a legitimate conclusionthat loss of articulate speech should result from destruction of the auditory word-centre, just as agraphia results from destruction of the visual word-centre. Ballet ${ }^{3}$ and Ross, ${ }^{4}$ following me, expressed very similar views, though the majority of writers have rather followed Wernicke, and regarded paraphasia as the natural accompaniment of worddeafness.

\footnotetext{
1 Lectures I. and II. were published in THE LANCET of April 3rd and April 10th, 1897, respectively.

The Brain as an Organ of Mind, 1880, p. 685

3 Le Langage Intérieur, 1886, pp. 91 and 166.
}

Now that more cases have been observed we are in a better position for throwing light upon this point. An examination of the recorded observations in which the lesion has been limited to the hinder part of the first, and perhaps also of the second, left temporal convolutions (without perceptibly encroaching upon the visual word-centre) shows surprisingly different results in regard to the nature and degree of the speech alteration met with. In some of the cases there has been aphasia; in others a more or less marked paraphasia; whilst in two or three of the cases the defect in voluntary speech has been less marked. Thus, looking to the same sixteen cases of destruction of the auditory word-centre to which I previously referred ${ }^{5}$ when. speaking of the frequency with which word-blindness and agraphia occur as additional symptoms, I find that what is described as "motor aphasia" existed in six of them (viz., in Mirallié's list Nos. '7, 11, 12, and 25; and in Amidon's list Nos. 14 and 18). In six of the cases also some amount of paraphasia existed (viz., in Mirallié's list Nos. 3, 4, 19, 21 , and 23; and in Amidon's list No. 7). In one case (Mirallié's No. 14) both aphasia and paraphasia are said to bave existed; while in the three remaining cases (Amidon's Nos. 6,15 , and 17) voluntary speech seems to have been rather less affected.

Thus it will be seen that we have all been more or less wrong; and I must confess that the revelation of these apparently contradictory results in the way of speech disturbance in association with word-deafness surprised me not a little. The meaning of such remarkable variations demands a careful consideration.

The three cases last referred to in which voluntary speech has been least interfered with are, I believe, altogether exceptional. One of them is a case recorded by Clans, ${ }^{7}$ concerning which, unfortunately, there are only a few meagre details.

CASE 22.-A man, aged sixty-eight years, understood nothing said to bim. He answered always wrongly, while be spoke correctly. His intelligence was weakened. His hearing was good. A focus of softening was found involving the left first temporal convolution, except its anterior third. This disorganised portion of the cortex and also the corresponding border of the second temporal convolution had a brown colour.

I have been unable to obtain any further particulars concerning this case, as the periodical in which it is reported is not contained in either of the libraries to which I have had access. It seems to be Case No. 20 in the "Table of Cases of Sensory Aphasia with Lesions and Symptoms" cited by Allen Starr, ${ }^{8}$ and there also no further details are given. No weight, therefore, can be attached to this example, the details of which are so incomplete. The second case is one that was originally recorded by Wernicke, ${ }^{9}$ and the following are all the essential details that are given.

CASE 23.-A woman, aged seventy-five years, was admitted to hospital on Oct. 7th, 1873, showing well-marked indications of old age. It was ascertained from her relatives that her speech had suddenly become troubled and almost lost on Nov. 2nd, 1872. On admission her psychical condition seemed to be that of a crazed person complicated with aphasia. Sbe mostly lay huddled up in bed, and suffered from incontinence of urine and of fæces. She answered all questions put to her quite wrongly, and did not attempt to do anything she was told. She paid little attention to her surroundings and showed no desire to make any communications concerning her distressing condition. Her spontaneous speech was comparatively insignificant, though it was sufficient to show she was not suffering from motor aphasia. Her speech trouble was further shown by her alteration and displacement of words. Thus she ofter said correctly "I thank you heartily" and another time "I thank you most gively,"\&c.; "I am quite ill" " "Ah ! how cold I am " "You are most gively," \&c.; "I am quite ill"; "Ah ! how cold I am" ; "You are a whom she had just called a kind gentleman she called soon after "wom she bad just called a kind gentleman she called soon after "mein Tochtel" or " mein Sohnel." An ophthalmoscopic examination on Nov. 5th, 1873, showed grey atrophy of the right optic disc. Sensisility seemed intact, and tbe hand-grip was weak, but equal on the two sides. More exact observations on these points were not made. There occurred as a result of intestinal troubles on Dec. Ist, 1874. At the

5 Excepting that I omit Mirallié's Case 10, and include instead his Case 2, where the only lesion beyond the destruction of the first temporal convolution was a very minute "plaque jaune," no more than a millimetre square, situated in the upper border of the foot of the third frontal convolution.

6 Numbers of the cases of "sensory apbasia" hitherto recorded are comparatively valueless for the purpose of any critical study of their symptoms, either on account of the nature, extent. and complication of the lesions, or from the paucity of the clinical details, or perhaps from two or three of these causes in combination. Among such more or less vague cases 1 include thirteen in Mirallies sist (viz. Nos. $2,15,18,20,22,27,28,32,33,34,35,36$, and 37), and three in Amidon's list (viz., Nos, 8, 9, and 22). In four other cases-namely, Nos. 10, 11, and 17 of Mirallié's list, and No. 20 of Amidon's-there was a lesion in Broca's centre as well as in the auditory word-centre.

Der Irrenfreumd, No. 6, 1883 8 Brain, $1890, \mathrm{p} 100$

9 Der Aphasische Symptomen-Complex, 1874, p. 43. 
necropsy there was found an increase in the sub-arachnoid fluid, and the convolutions generally of both hemispheres were somewhat wasted. There was also an excess of fluid in the lateral ventricles. All the "orain arteries were highly atheromatous, and there was thrombosis of some of the terminal branches of the left middle cerebral artery. The marginal lobule were in a state of yellow softening. The island of Reil was intact.

It will be seen from the above particulars that this patient's spontaneous speech was extremely limited and that she made frequent mistakes in words and in their pronunciation. The statement contained in Amidon's abstract, therefore, that her "spontaneous speech was very good," certainly goes far beyond what there is any warrant for. It is worthy of note also that the auditory word-centre may not have been entirely destroyed, since the second temporal convolution seems not to have been at all involved. In the previous case, reported by Claus, it should also be observed that the second temporal convolution was only very slightly involved. It is merely said that its upper border was affected ("had a brown colour").

The third case, curiously enough, has often been quoted as though it were a typical example of word-deafness rather than one of an unusual character. It was recorded by Giraudeau, ${ }^{10}$ and some of the principal details are these.

CASE 24.-The patient, a woman, aged forty years, had previously wnjoyed good health, though she had never menstruated. For three months before admission to l'Hôpital St. Antoine she had suffered from a constant beadache, with nocturnal exacerbations of such a character as to render sleep impossible. There had been no vomiting or epileptiTorm attacks. For upwards of a month before admission she was rabe the game time it inas observed that she no longer understood what wos ins 3ospital. On admission the patient was found to be very stout; there aspital. On admission the patient was found to be very stout; there
was no fever, the right pupil was slightly dilated, and there was severe was no fever, the right pupil was slightly dilated, and there was severe
headache. When asked her name she raised her head, but did not headache. When asked her name she raised her head, but did not
answer. When asked a second time she answered, "What do you answer. When asked a second time she answered, "What do you don't understand." When asked a fourth time she answered correctly, don't understand." "When asked a fourth time she answered correctly, she evinced the same difficulty of understanding, but replied, after a time, "Three months." When asked to give her address she replied, "Perhaps for three months and a half." Being interrogated as to her occupation, she presented the prescriptions of the physician who treated "her in the town, and added, "A white powder" (sulphate of quinine). On several occasions we changed the mode of our interrogations, but the replies of the patient were always analogous to those mentioned
above. After having by great difficulty made her understand a question by frequent repetition she answered; but whatever subsequent questions were put to her she followed her first idea, and her sub sequent replies had no relation whatever to the questions put to her. Sometimes, however, it was impossible to make ber understand our meaning at all, and to every question addressed to her she sinvariably replied: "What do you say? I don't understand. Cure me." Her hearing however, was unaffected; there was no discharge from the ear; she heard the ticking of a watch, and turned her head at any slight noise made near her. Vision was good in both eves, and there was no word-blindness, for ahe could easily read the headings of the bed-ticket and written questions put to her, to which she replied verbally or in writing after a little reflection. Tactile sensibility was preserved, as well as the senses of taste and smell, and her motor power was unaffected. Without entering into further details, suffice it to say that the psychical affection ravidly increased, and on the ninth day after her admission the word-deafness was complete, and whenever she was addressed she invariably said. "I do not understand," and then began $t 0$ weep. The next day she fell into a state of coma and died. At the veeropsy a sarcomatous tumour of the size of a walnut was found ocenpying the posterior part of the first and second temporo-sphenoidal convolutions of the left hemisphere, the rest of the brain being healthy.

Here the details are fortunately more ample. Although this patient's speech was limited, there was clearly neither aphasia nor paraphasia, and tbis may, I think, be explained either by supposing that the lesion in the early days did not Jestroy the whole of the auditory word-centre-which is more shan possible seeing that the lesion was a tumour and also that the word-deafness was not absolute; or else that the patient was a strong "visual "-a person, therefore, in whom the excitation of Broca's centre might have been brought abouts direstly from the visual word-centre, both in spontaneous speech and in reply to written questions. And to the latter she is expressly said to have replied "verbally or in writing, after a little reflection." This vossibiiity might, of course, be applicable also in explanation of the other two cases.

There is an interesting point worth noticing here in reference to cases of parial word-deafness, illustrating the increased power of recollection or comprehension when two ar more bonds of association are simultaneously called into activity. Thus, in a case of incomplete word-deafness observea kg Fränkel, when the patient was asked, "What is a fork?" te replied, "I don't know what you say." But when a fork was shown to him at the same time that its name was pronounced he not only recognised the fork, but comprehended its name and repeated it, the visual image of the object here helping to revive the auditory image of the word. At other times when this same patient was questioned, at first he did not understand, but he would struggle to articulate the words used and would thus, after various attempts, arrive at the meaning of the question. Another instance in which visual impressions were habitually called upon to aid a damaged auditory centre was long ago recorded by Abercrombie in his "Inquiry into the Intellectual Powers," where he says (seventh edition, 1837, p. 158) "The gentleman to whom it referred could not be made to understand the name of an object if it was spoken to him but understood it perfectly when it was written. His mental faculties were so entire that he was engaged in most extensive agricultural concerns, and he managed them with perfect correctness by means of a remarkable contrivance. He kept before him in the room where he transacted business a list of the words which were most apt to occur in his intercourse with his workmen. When one of them wished to communicate with him on any subject he first heard what the workman had to say, but without understanding him further than to catch the words. He then turned to the words in his written list, and whenever they met his eye he understood them perfectly. These particulars I had from his son, a gentleman of high intelligence."

This slight digression may serve to illustrate one of the two suggestions I have made in explanation of the comparatively slight defects in speech presented by the three altogether exceptional cases of word deafness to which I have above referred. But, before pursuing our attempt to explain the differences presented by the other cases, it will be well first of all to see what the results have been in two other sets of cases involving destruction of the left auditory word-centre as one component of the existing lesions-that is to say, in the two next sets of cases already cited for consideration-viz., (2) the cases in which there have been combined lesions of the auditory word-centres in each hemisphere ; and (3) the cases in which the auditory and the visual word-centres have been destroyed or severely damaged in both hemispheres.

\section{(2) Defeects Resulting fRom Lesions of the Auditory} WORD-CENTRE IN EACH HEMISPHERE.

Cases of double lesion in the upper temporal convolutions are extremely rare. Only four such cases are known to me, and concerning these clinical details in three are unfortunately extremely meagre, consisting of particulars obtained from friends or others, rather than from the examination by a skilled observer.

The first of these cases to which I will refer is one that has been recorded by Kähler and Pick, ${ }^{11}$ though the details are very scanty and of the kind above mentioned.

CASE 25.-A woman, aged forty-two years, was seen eighteen months after the attack. Her husband stated that she suffered from headache for three months, when loss of speech and hearing supervened, and symptoms of apparent dementia. She uttered inarticulate sounds almost all day long. She was after a time admitted to an asplum, where she remained for six months, to the date of her death. Whilst there she ccntinued to mumble constantly, the only articulate sounds she uttered being "Tschen" and "Tscho." She occasionally moved her head when spoken to as if she heard, though she did not understand what was said. There was no paralysis or other motor disturbance. At the necropsy there was congestion of the membranes, the frontal and parietal convolutions were somewhat wasted, the sulci being wide and filled with serum. Over the left temporal lobe the pia was jelly like, whilst its convolutions were swollen, pressed together, and of soft, jelly-like consistence. The right temporal lobe was also slightly softened. Sections showed that the softening was confined to the cortex and on the left side to the same region. The foot of the third frontal convolution was not involved.

The second case is one that has been recorded by C. K. Mills, ${ }^{12}$ and although the details of the necropsy are full and all that could be desired, the patient only came under his observation a few days before her death when she was very weak and ill, suffering from the effects of an old valvular aisease of the heart. He says: "Some of the facts of her history were obtained from relatives who came to see her at the hospital, and others were procured after her death from a brother and sister-in-law, whom I sought out and carefully interviewed." The following are

11 Vierteljahresschrift für Praktische Heilkunde, No. 1, 1879, p. 6. 12 Philadelphia University Medical Magazine, November, 1891; and Brain, 1891, p. 468 . 
The LANOET,] DR. BASTIAN : PROBLEMS IN APHASIA AND OTHER SPEECH DEFECTS. [APRIL 24, 1897. 1139:

all the particulars given that are of any importance from our point of view.

CASE 26.-A woman, aged forty-six years, was admitted to the Philadelphia Hospital in August, 1891. Fifteen years before her death she had an apoplectic attack which left her word-deaf but not para-
lysed. Prior to the first attack of apoplexy her hearing had been good, lysed. Prior to the first attack of apoplexy her hearing had been good,
hut after it she could not by hearing understand anything that was said to her. She could, however, hear music and sounds of various kinds; for instance, when an organ or band had performed in the street she at times had called attention to the fact, and she had also come down from the second or even the third storey to open the front door in answer to a knock. She could hear such sounds as a bell ringing and a clock ticking. These facts were elicited from her relatives through various statements made by them, chiefly spontaneously. When anyone wished to communicate with her it was done by means of writing or signs, as she had fully preserved her vision and was evidently not word-blind either for writing or printing. She often read the newspapers, and could do so with intelligence up to a few have been long after the destruction this is remarkable, as it would Her sister-in-law said that several times she had heard her try to read the newspaper aloud, and in so doing she had seemed to understand what she read, "but made a tangle of her words." From the me of the flrst attack she had jever been able to speak well, her words becoming jumbled or targled. From the description given of phasia and paralexia. Her relatives spoke positively of her deafness as haring been due to the "stroke"; but the apoplectic attack, although it had at once caused this word-deafness and paraphasia, had not in any way, as far as could be ascertained, affected either motion or sensation She could write, but "sometimes mixed up her words in writing." Nine years before her death she had another and more severe apoplexy, after which her deafness increased for sounds as well as words until it was almost total. This seizure left ber also with partial left hemi-
plegia, chiefly affecting the arm. Dr. Mills adds: "She was first examined by me on Aug. 24th, 1891. Her condition then was one of almost complete helplessness. It was impossible to make her unrler stand what was said to her, and, so far as could be determined hy repeated tests, she was totally deaf; but notwithstanding her weakness, helplessness, and deafness, her face had a somewhat intelligent expression. She looked about her as if she knew what was going on. She was very emaciated; her heart's aciion was excited, and examination showerl the presence of marked nurmurs, both mitral and aortic She became feebler day by day, and died Aug. 28th." At the necropsy the posterior two-thirds of the left first temporal contolution was found to be shrunken to a thin strip, and the posterior fourth of the second temporal convolution was also atrophied. The other left temporal convolutions were healthy. On the right side there was an old and very extensive hæmorrhagic cyst, which had completely destroyed the first and almost completely the second temporal convolution, as well as the island of Reil and other parts in the immediate neighbourhood. (Very full details of the condition of the brain are given, and in the Philagravures showing the extent of the lesions.)

This is undoubtedly a very important case, especially from the point of view of cerebral localisation, from which standpoint Mills principally deals with it. It is interesting to find that after the patient became word-deaf, owing to the first lesion on the left side, there was no word-blindness, as "she often read the newspapers and could do so with intelligence"-although some would have us believe that even the destruction of Broca's centre, which is so much further away from the visual centre, causes alexia. There was, however, paraphasia and paralexia. Unfortunately there is no definite statement as to what alteration took place in the patient's speech after the lesion occurred on the right side-that is, nine years before her death. I therefore wrote to Dr. Mills to ascertain whether he could supply any further information on this important point, and his reply is as follows: "She was admitted to the hospital some little time (probably two or three weeks) before I examined her, and my recollection is that it was reported to me that she had not spoken during that time, but more than this I cannot say ...... and unfortunately I have no longer the means of verifying $m y$ recollection. She certainly was not able to speak, or at least did not speak, at the time of my examination." I will merely add that, from the fact of the word-deafness in this patient not being associated with word-blindness, it does not necessarily follow that the paraphasic speech should have been lost-that is to say, that there should have been speechlessness-immediately after the occurrence of the lesion in the right hemisphere. There is the possibility that she might have been one of those "visuals" capable of speaking, thongh in a disordered fashion, by the direct action of the visual word-centre upon Broca's convolution. It seems pretty clear, however, from what Dr. Mills says, that at the time she went into the hospital she was incapable of speaking. Still, it is important to bear the above-mentioned possibility in mind, as it is one to which we shall have to recur.

The third case is one that was recorded by Wernicke and Friedländer ${ }^{13}$ and an abstract of it has been given by Ferrier ${ }^{3 *}$ which I will now quote.

CASE 27.-A woman, aged forty-three years, who had never suffered from deafness or affection of vision, was attacked on June 22nd, 1880, with right hemiplegia and aphasia. She remained in the hospital until Aug. 4th, when she was discharged. At this time the patient could speak, but she spoke unintelligibly, and was sometimes believed to be intoxicated. She not only could not make herself understood, but she could not understand what was said to her. She was received into the hospital again on Sept. 10th, with slight paresis of the left arm. The right hemiplegia had entirely disappeared. The patient was looked upon as insane She was absolutely deaf, so that she could not be communicated with. She died from an attack of hamatemesis on Oet. 2lst. An extensive lesion was found in each temporal lobe (of which fignes are given). On the left side it involved the posterior half of the first and second temporal conrolutions and a small part of the third; on the right side it involved the angular gyrus, the posterior extremity of the upper temporal

The fourth case bas been described by Pick. It is one of great importance, but as it is also one of a very exceptionat nature I reserve its consideration for the present.

\section{(3) Defects Resuliting from Destruction OF The} AUDITORY AND VISUAL WORD-CENTRES IN

\section{EACII HEMISPHERE.}

There is only one case known to me in which there com bined lesions have existed in the two hemispheres, although there is another with which it will be not uninteresting to compare it where complete blindness and deafness had been produced in infancy by peripheral lesions.

The case definitely belonging to this category was reported many years ago by J. C. Shaw, ${ }^{15}$ but unfortunately in this as in other rare cases many essential details are omitited. Still this case is so valuable by reason of its extreme rarity that we are glad to accept it now withstanding tbe paucity of clinical details. All tbe essential recorded fac:s are these.

CASE 28.-A woman, aged thirty-four years, was admitted into King's County Lunatic Asylum on sept. 25th, 1879. A few facts concerning her were obtained from a sister. Two montbs hefore almission she complained of being unalle to use the right arm. Goon aiterwards she had a sudden attack characterised by loss of consciousness, inability to speak, and loss of hearing. They did not notice at this time that
she had any loss of vision. She is said to have remained "nncon. she had any loss ot vision. She is said to have remained "uncon began to talk. But she could talk sensibly only for a few minutes. then she would ramble and lecome incoherent. The friends. were indefinite as to the extent of her sight trouble at thi time, but there seems to have been marked mental disturbance. The certificates committing her relate that "she says some men are trying to kill her; she screams without cause; and sho is at times violent." The following meagre notes concerning her condition are then given:- "On admission she is found to be very stupid. does not answer any questions, evidently does not hear them; is quite deaf. Pupls slightly dilated and équal; she is evidently quite blind. Physical condition poor; habits dirty. Oct. 18th and Nov.21st: Had tests of tactile sensibility and smell show them to be unimpaired, but tests of tactile sensibility and smell show them to be unimpaired, but
she is absolutely deaf to all noises and also blind. Dec. 16th : Walks about the hall using disconnected and unintelligible words; at times spouking very loudly and screaming. Jan. 31st, 1880: Severe convalspeaking very loudy and streaming. Jan. 31st, 1880 : Severe conval-
sions lasting seven hours. Muscular spasm most marked on left side (the right arm remained contracted afterwards during two days). Feb. 14th: Is up again; walks about; shows no sign of paresis any where. October. She ; walks about; shows no sign of paresis anyo unintelligibly night and day; is growing thinner and more stupid. if that were prsible" Th; prow if that were pnssible." The patient remained in about the same pneumonia and died on Sept. 19th. At the necropsy an almost exactly symmetrical patch of cortical atrophy was found in each hemisphere. It involved (as is shown by two figures) the greater part of the upper temporal and angular gyri, the marginal lobule, and the upper parietal lobule on each side. In the affected areas it was found "that the grey matter had entirelv disappeared, leaving the very outer layer to which the pia was attached and the white matter below, so that there was really a cavity or space between the two, formed at the outer layer to be composed of dense connective tissue filled with nuclei" There was no atheroma of the great vessels, and, except that the patches of cortical atrophy mentioned involved on the left side a small portion of the upper part of the ascending parietal, and on the right side a portions of the brain seem to have shown no appreciable lesion.

It is interesting to find also that in the celebrated case of Laura Bridgman, who was totally deaf and blind from about the end of her second year, her power of uttering articulate sounds was not very different in kind, though less in degree, than that which was met with in the rase above recorded. The following account of her condition in this respect is given by Kussmaul ${ }^{16}$ :-

CASE 29.-The child lost her eyesight and hearing absut the end of her second year, when she was beginning to talk, and in consequence soon lost the power of speech. Now, although it may be assumed that she retained no memory of sounds, which long experience teaches us is the rule with those who become denf-nutes so early, yet ohe was able to produce a multitude of snunds. She took the greatest pleasure in

15 Archives of Medicine, New York, 1882, p 8C.

$$
16 \text { Loe. cit., p. } 634 \text {. }
$$


giving utterance to these, and even went so far occasionally, in order to indulge herself in noises to her heart's content, as to lock herself up when her teachers endeavoured to restrain her from so doing. These noises were, in fact, inarticulate-e.g., a kind of chuckling or grunting, an expression of contentment; while others-e.g., "h- $\alpha-p h-p h$ "-were better formed, and served for an indication of astonishment. Other sounds, again, she elevated to the dignity of names, and bestowed
them on certain persons. She uttered these latter when those so denominated apprcacbed her, or when she wanted to find them, or even at times when she only thought of them. She employed some fifty or sixty such sounds as names, many of which could be written down, such as fu, tu, pa, fifpig, ts, pr, lutt, \&c.; manly, however, it would be almost impnssible to express in letters. Sbe formed, however, only words of one syllable, but frequently re-duplicated them two or three times, as fu-fu-fu, tu-tu-tu.

There was therefore slowly developed in this child something more of method in the use of the simple or complex sounds that were uttered than has been met with in the early stages, or for some time after the onset, of the cases of disease in which both auditory word-centres have been destroyed. The sounds emitted were also less voluble and free, which is only to have been expected, seeing that in Laura Bridgman the glosso-finæsthetic centres bad never been developed as they have been in the case of patients who, by reason of the lesions above mentioned occurring in adult life, have been reduced to a condition in which their speech has become unintelligible. The powerlessness of Broca's centre when unaided for the production of anything like intelligible speech is, however, clearly shown.

After the narration of these additional cases in which there was a destruction of the auditory word-centre in each hemisphere we may now with more advantage return to the question why in a certain number of the cases of destruction of the left auditory word-centre alone there is (1) an aphasic loss of speech, in others (2) paraphasia, and in still others (3) a comparatively slight impairment in voluntary speech.

My original contention was that an aphasic loss of speech is what is naturally to be expected as a result of such a lesion, if we are to suppose, as seems highly probable, that the auditory word-centre in the great majority of persons holds a relation to Broca's centre similar to that which the visual word-centre holds to the writing centre. It would appear, therefore, that what stands in need of explanation is the occurrence of the second and third class of cases-namely, those in which more or less marked paraphasia, or even fair speech, has existed.

The evidence in favour of the posterior half of the upper, with perhaps the posterior part of the middle, temporal convolutions being the chief, if not the exclusive, seat of the auditory word-centre must be regarded as very conclusive. ${ }^{17}$ The difference in voluntary speech power presented by the cases above referred to cannot therefore be explained by the supposition that the auditory word-centre has not yet been properly localised.

The various possibilities that suggest themselves to me in explanation of the differences in the degree of impairment of speech in different cases in which lesions have been found in the left auditory word-centre are as follows:-

(a) There is the possibility that in some of the cases in which the word deafness has been complete whilst voluntary speech has been fairly good the auditory wordcentre has been rather isolated from its afferent fibres than destroyed. These would be cases in which the amount of damage to the auditory word-centre itself was small-cases approaching those named by Lichtheim "isolated speechdeafness," which will be subsequently considered.

(b) Then in some cases the auditory word-centre may be damaged sufficiently to prevent perfect comprehension of speech, though it may still be sound enough with the aid of the visual word-centre for the production of paraphasic speech. This might afford an explanation of certain cases in which there is only partial damage of the anditory wordcentre, together with incomplete word-deafness, as in No. 7 in Amidon's list, and Nos. 2 and 48 of Mirallié's list, as well as in a case by West, ${ }^{13}$ which is not included in either of them.

(c) In other cases, where the individuals affected are strong " visuals" the paraphasic speech may be produced by the action of the visual word-centre taking the place of the auditory word-centre-that is, by the passage of the stimulus directly from the visual word-centre to Broca's region across the commissure $e \ell$, as represented in Fig. 5. Such an explanation may be applicable to some of the cases

17 On this subject ser Fryer on Cerebral Localisation, 18c0, and C. K. Mills, in Brain, 1891 . where the destruction of the auditory word-centre has not produced word-blindness as well as word-deafness. And this, as we have seen, bas been what has occurred in about twothirds of the recorded cases. ${ }^{1}$

There is one extraordinary case that has been recorded by Pick ${ }^{20}$ which seems, moreover, quite incapable of being understood except by the supposition of the adequacy of the direct action of the visual word-centre upon Broca's region even for the production of correct speechas it is brought about, in fact, in all deaf-mutes who are taught to speak. This is the case of lesion in the upper temporal convolutions of each hemisphere, the consideration of which was deferred because of its altogether exceptional character. Although this patient was perfectly word-deaf, he was able to speak correctly, to read correctly, and to comprehend writing perfectly, as may be gathered from the following details.

CASE 30.-A day labourer, aged twenty-four years, was completely word-deaf and behaved like a deaf person, taking no notice of ordinary sounds near him. It was found that he only readil Yot cals, clapping, or ringing of belis, and this not always readily. Yet if one shouted to him unexpectedly, he said, angrily quite well but I don't understand; I can hear a fly flying past me." His power of recognising airs previously known to him seemed to be also lost. power of recognising airs previously known to him seemed to bealso lost. His speech was perfectly correct. He spoke fluently, and only to him correctly. He could not repeat words or phrases. Writing was executed slowly but quite correctly, though he could not write from dictation. With regard to his power of copying nothing could be stated, as he could not be persuaded to make the attempt. He read aloud easily and quite correctly, and he understood both print and writing perfectly. Writing afforded the only means of communicating with hin apart from gestures. The patient's condition in the above mentioned respects remained essentially unchanged during the whole period of his stay in the hospital, from Jan. 17th to May 12th, 1891. At the necropsy and of a yellow colour. On the left side the posterior half of the upper temporal convolution and the supra-marginal gyrus were the parts that were softened. The island of Reil was intact. On the right side there was softening of the upper temporal convolution and a great part of the second temporal, as well as of the island of Reil, together with some small convolution.

It appears from the history of this patient that the first lesion occurred on the right side of the brain about ten years before his admission to the hospital. Six years later the lesion in the left hemisphere occurred. which resulted in the production of word-deafness. Speaking of this patient's condition during the four months that he was under observation Pick says that his intelligence was distinctly weakened and his behaviour childish. It was difficult to fix his attention; he was very emotional and spent much time in prayer. When so engaged no sort of noise seemed to disturb him, for, notwithstanding what he said as to his hearing, it appears that, like Lichtheim's patient, ${ }^{21}$ he was also really very deaf to ordinary sounds. As above stated, there seems no way of explaining this case except by supposing that the left visual word-centre was capable of acting directly upon Broca's centre, and without any aid from the left auditory word-centre (the destruction of which had caused the word-deafness four years previously) of acting so effectively that the patient was capable of reading aloud and of speaking, even without making mistakes in words. The word-deafness was clearly caused by the lesion in the left auditory word-centre itself, and it seems equally certain, therefore, that this centre could not have been instrumental in enabling the patient to speak. It is superfluous, consequently, to look for a sub-cortical lesion. ${ }^{2}$

(d) Another possibility in explanation of the preservation of slight or disordered speech after destruction of the left anditory word-centre is that the auditory word-centre of the right hemisphere acts, by means of commissural fibres passing obliquely through the corpus callosum, upon the left third frontal convolution. This is a possibility which has not, I believe, been previously suggested by any writer on speech defects, though it seems to me almost the only means of accounting for the existence of speech of a paraphasic type in those cases where the destruction of the left auditory word-centre leads to word-blindness as well as to word-deafness-that is, in about one-third of the total number of such cases. The addition of word-blindness as a symptom in these cases must, as I have said, be supposed to

19 The next explanation is, however, equally applicable to this class of cases as well as to those in which word-blindness co-exists with the word-deafness.

$$
20 \text { Archiv für Psychologie, 1892, p. } 909 .
$$

Yet Mirallié actually quotes it as an example of a sub-cortical 
be due to the very close functional and topographical relations of the auditory and the visual word-centres; but if the visual word-centre has had its functional activity so deranged as to have led to word-blindness it cannot reasonably be supposed that it could in that state take on independent functions in the way of supplementing the activity of the destroyed auditory word-centre.

The argument in favour of the possible action of the right auditory word-centre in the manner indicated is, however, even stronger than that just stated, because we shall find in a future section, when dealing with cases in which there has been more or less complete destruction of both the auditory and the visual word-centres of the left hemisphere, that out of fifteen of such cases, in two speech is reported to have been fairly good, in seven there was jargon speech or paraphasia, whilst in six it was more or less markedly aphasic. But when the auditory and the visual word-centres of the left hemisphere are destroyed speech, if it is to be produced by that hemisphere alone, would have to be effected solely by Broca's centre. We have, however, already seen that with double destruction of the auditory word-centre, as well as with double destruction of the auditory and the visual wordcentres, speech has always been rendered unintelligible, except in one single case-that of Pick, above recorded. It thus seems to stand out very clearly that Broca's centre alone is not capable of acting as an instigator and adequate guide for the production of intelligible speech. We have good reason for believing, moreover, as I have previously pointed out, that it is not a centre whose images are much used as counters for thought, although the rousing of the sub-conscious memories of this centre is, under proper guidance, essential for the production of speech as a series of voluntary movements.

We are therefore absolutely driven to look for aid or guidance from the right hemisphere if we are to account for the production of even paraphasic speech in cases of damage to the left hemisphere of such a nature that worddeafness is associated with word-blindness, whether the latter be of structural or of functional origin. This same hypothesis enables us to understand the unintelligible character of the speech in three out of the four cases cited of double destruction of the auditory word-centre, as well as in the case in which the auditory and the visual wordcentres were destroyed in each hemisphere. The old notion that intelligible speech can be initiated and produced by the influence of Broca's centre alone must be absolutely renounced.

By reference to other considerations it may also be shown to be by no means devoid of probability that both auditory word-centres are actually in structural relation with, and therefore capable of acting upon, the glosso-kinæsthetic centre of the left hemisphere. It will not be difficult to show that the notions hitherto prevalent in regard to the understanding of spoken and written language and the utterance of speech have probably left altogether too much out of account that conjoint activity of the right and left hemispheres which almost certainly exists in connexion with perceptive processes, and which therefore we may suppose exists in connexion with derivative intellectual processes, as well as during the initiation of all sorts of motor reactions directly or indirectly following thereupon.

It is well known that each olfactory bulb and that each retina is connected with both cerebral hemispheres. Modern knowledge compels us to believe that in every act of visual perception the half-vision centres in each occipital lobe are called into concurrent activity. It would be contrary to existing knowledge for us to suppose that the cochlear fibres of the auditory nerve come into direct relation with each hemisphere, although Lichtheim does make an assumption to that effect. ${ }^{23}$ On this subject of the intra-cerebral distribution of auditory fibres Foster says ${ }^{21}$ the evidence derived from "secondary degenerations" "suggests that the path of auditory impulses is along the cochlear nerve to the lateral fillet of the crossed side, and so by the posterior corpus quadrigeminum and median corpus geniculatum to the cortex of the temporal lobe of that crossed side." Still, this distribution cannot yet be considered quite settled, so that, as Foster adds, "the matter needs further investigation."

The probabilities are, however, that each auditory nerve is indirectly connected with each hemisphere through the intermediation of commissural fibres between the two upper temporal and other convolutions in each temporal lobe, constituting the cortical seat of this endowment-such commissural fibres forming part of the corpus callosum. ${ }^{25}$ In this way, therefore, a provision exists for the conjoint activity of the two hemispheres in connexion with the sense of hearing. In healthy persons auditory impressions pass equally to the two sides of the brain, and it is commonly supposed that minute differences in intensity of the impressions, dependent upon the source of the sound in relation to us, enable us principally to judge of the direction whence the sound emanates. Although we have no distinct proofs other than those of an analogical order that the general auditory centres are connected by commissures, we have proof that the specialised portions of them known as auditory word-centres must be so connected. Had it not been for the existence of such a connexion word-deafness would result from absolute deafness in the right ear (whether due to labyrinthine or to middle-ear disease), owing to the left auditory word-centre being cut off from all afferent impressions, as I pointed out some years since. ${ }^{26}$ We know, however, that this does not occur; therefore impressions must reach this centre through the left ear, the right auditory word-centre, and thence across the commissure in the corpus callosum. And the fact that in such cases the comprehension of speech seems not to be diminished would point, I think, to the probability that the right auditory word-centre is about as well developed as the left on its receptive side. ${ }^{27}$ And if that be so, is it to be supposed that it would remain functionally inert, save in the case of the accidental supervention of right-sided deafness?

Clinico-pathological investigations have long since taught us in an unmistakeable manner that the right auditory word-centre usually exercises (in right-handed persons) little influence upon the glosso-kinæsthetic centre of its own side; and now I would urge that new clinicopathological observations should strongly incline us to believe that it must to some extent coöperate with the left auditory word-centre in the excitation of Broca's region for the production of articulate speech. We have seen that instances of paraphasic speech in cases of word-deafness associated with word-blindness are only capable of being explained in accordance with some such hypothesis, and there is the additional fact that speech has been found to be so much worse (with one exception) as to be quite unintelligible when both the auditory word-centres have been destroyed.

A difficulty that presents itself in connexion with such views as I have just been expressing is to account for the non-production of any amount of word-deafness from disease of the right auditory word-centre alone. It might be thought that even if the left auditory word-centre exercises an altogether preponderant influence in connexion with the comprehension and the production of speech, still the destruction of the auxiliary right auditory word-centre ought to produce effects of some kind, of a temporary if not of a permanent nature. Extremely little evidence, however, is available upon this subject, and it is one to which most careful attention should be given in the future. ${ }^{23}$ We know, of course, that in left-handed persons the predominant activity of the auditory and the visual wordcentres is in the right hemisphere, and that consequently in them we may get as a result of lesions in this hemisphere either word-deafness or word-blindness or both, just as we may get aphasia either alone or in association with left hemiplegia. Such cases of so-called " sensory aphasia" due to lesions in the right hemisphere bave been recorded by Kussmaul ${ }^{29}$ and also by Bernheim, ${ }^{30}$ and there are doubtless many others. There was also a typical case of amnesia verbalis due to a right-sided lesion recorded by Trousseau. ${ }^{31}$

In what $I$ have said hitherto I have only been contending

The anterior commissure seems mainly to connect the convolu tions of the tip and under surface of the temporal lobe, so that it is more probable that its upper and posterior regions should be brought into structural and functional relation through fibres of the corpus callosum.

26 Paralyses: Cerebral, Bulbar, and Spinal, 1886, p. 267.

27 On this subject see what has already been said towards the end of the last section but one of the first lecture.

2s What has just been said concerning the right auditory word-centre applies almost equally strongly to the right visual word-centre. We want to know also to what extent and for how long the comprehension of written and printed words is impaired by destruction of the right angular gyrus and supra-marginal lobule.

29 Ziemssen's Patbologie und Therapie, Band xii., 1876, p. 168.

1 Lectures, trano Revue de Médecine, 1885, p. 625

as my Case 16.

R 2 
for the existence of another special illustration of a general th principle which bas previously been strongly adrocated by others-namely, that of the double representation of movements in each hemisphere of the brain. Indeed, for many years Hughlings Jackson has gone further still, and has adranced the speculation ${ }^{32}$ "that all parts of both sides of the body are represented in each balf of the brain." Definite evidence on this subject was brought forward by Goltz, who, at the Physiological Congress in Basel in September, 1889, showed a dog from which almost the whole of the left hemisphere had been removed, and from whose behaviour, as demonstrated to the Congress, he felt able to announce the following important conclusions $^{33}$ : "Each cerebral hemisphere is in connexion with the voluntary muscles of both halves of the body. It appears, however, that the connexion between one cerebral hemisphere and the muscles of the opposite half of the body is more converient than that on the same side. Hence a dog whose left hemisphere is destroyed prefers to use the left paw, because the will impulses from the right hemisphere flow by more convenient paths to the left limbs." He showed that sensibility was also present, and only somewhat impaired, in the right limbs of this dog. On the death of the animal the brain was removed, and was subsequently submitted to a most thorough examination by Langley and Grünbaum, who, at the conclusion of their report, say ${ }^{34}$ : "We have seen that in this dog there was on the left side no part of the cortex remaining except a small portion of the hippocampal convolution, and a little grey matter round the optic chiasma; that the left corpus striatum had been removed, and that the nerve cells of the left optic thalamus had degenerated. Notwithstanding this, it appears from Professor Goltz's account that the animal retained voluntary power over all its muscles and could feel in every part of its body." So far as the production of movements is concerned, these results are harmonious with the well-known results obtained by Franck and Pitres, ${ }^{35}$ who, after removing the so-called motor cortex on one side in a dog, found on faradaisation of the opposite cortical region that a convulsion was pro duced which involved first the limbs of the opposite side and then those of the same side of the body. Although this evidence tends in the same direction, it is not nearly so conclusive as that of Goltz. ${ }^{36}$

There is likewise actual evidence tending to show that

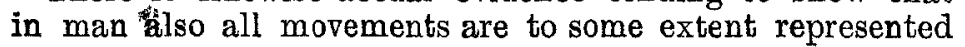
in each hemisphere of the brain. The representation of bilateral movements, as Broadbent originally pointed out, is commonly pretty equal, whilst that of limb movements is very unequal, being strong for the independent movements of the opposite limb and weak for the corresponding movements on the same side of the body. In support of this double cerebral representation there is the well-known fact that in hemiplegia some amount of paresis exists also on the opposite side of the body (that is, on the side of the brain lesion). There is also the well-known fact that in cases of large lesions in one hemisphere occurring in early life defects of sensibility are often even more thoroughly recovered from than the motor defects. 37

What has already been said tends to show that bilateral arrangements of different kinds exist in the brain more or less analogous to that which I now postulate, namely, that Broca's centre is connected with both auditory wordcentres-very intimately with the centre of the same side, and less intimately with that of the opposite side. The fact, moreover, that there are half-vision centres only in each hemisphere would seem to make it highly probable that $\mathrm{fcr}$ the voluntary performance of movements of one hand and arm, as in writing, there must in undamaged brains also be concurrent activity of these two centres brought to bear upon

32 Brit. Med Jour., vol. i. 1884, p. 593.

33 Journal of Physiology. 1890, p. 608. 34 Loc. cit., p. 634.

Archives de Physiologie, Aug. 15th, 1883

36 It has been shown by Sherrington and others in their studies of "secondary degenerations" that some of these double motor effects may be accounted for by the distribution in the cord of the fibres of the pyramidal tracts. It is known also that Broadbent explains some of the bilateral movements by reference to commissures existing between functionally related bilateral centres in the cord. But the voluntary movements of the right fore-paw in Goltz's dog must have implied the development in the only existing right hemisphere of the animal of all the nervous arrangements needful for the "conception" of separat movements in this right limb, that is, the passage to it and registration of kinæsthetic impressions from this limb, as well as the bringing of this centre into relation with the visual centre, in the manner that would be needful for the production of its voluntary morements. needful for the production of its voluntary morement the cheiro-kinæsthetic centre during the conception and voluntary initiation of the movements. It has long been known that a functional activity of the visual centre is as essential for the conception and initiation of voluntary limb movements as a functional activity of the auditory centre is for the initiation of the voluntary movements concerned with speech. It would seem, there. fore, as if in each case we have double auditory or double visual centres exercising their influence upon a kinxs. thetic centre in the left hemisphere, in which speech movements have been registered in the one case and writing movements in the other.

The existence of the kind of nervous arrangements that I have been endeavouring to indicate in the two hemispheres would clearly necessitate the presence of numerous fibres in the corpus callosum having an oblique direction, in addition to those that are more directly transverse. It is well known that for long Meynert's view was generally accepted, to the effect that the fibres of the corpus callosum only serre to connect similar regions in the two hemispheres. By the careful study of the course of "secondary degenerations" in the corpus callosum resulting from lesions of different parts of the cortex Sherrington has, however, shown that this was an erroneous view. He has found ${ }^{38}$ that not only similar but dissimilar parts of the two hemispheres are connected through this commissure. In regard to some inquiries of mine concerning this subject Sherrington writes: "My evidence was in part, as you suggest, the obliquity of the fibres, and also in part the spreading of them. ...... I found the degenerations from even circumscribed lesions of the fronto-parietal cortex spread considerably, especially after crossing the corpus callosum. I saw nothing at all incom. patible with what you urge, but anatomically everything in favour of it."

There is another point of great interest in this connexion, and that is the greatly increased development of the corpus callosum in man as compared with that in the brain of the great man-like apes. We have it on the excellent authority of the late Professor Marshall ${ }^{39}$ that the bulk of the corpus callosum, in proportion to the size of the brain, is twice as great in man as it is in the chimpanzee. It is only fair to assume that this relatively enormous increase in the comparative bulk of the corpus callosum is due in large part, either directly or indirectly, to man's acquirement of language and all the mental and moral development that has grown out of it.

\section{(4) Defects Resulting from Isolation of THE LeFT AUDITORY WORD.CENTRE.}

A clinical condition is produced by the isolation of the left auditory word-centre-that is, by the cutting it off from all its afferent fibres - which was first described by Lichtheim in 1884, ${ }^{, 0}$ upon the basis of a single case of word-deafness that seemed to differ from all others that had been previously recorded. To this condition Lichtheim gave the name of "isolated speech-deafness." It has been spoken of also by Wernicke as "subcortical word-deafness," whilst lately a similar condition has been described by Déjerine (who seems to have been oblivious or unaware of Lichtheim's case) under the name of "pure word-deafness." The state itself is simple enough, though an extremely interesting one. It is the condition of a partially deaf man, the deafness being not general, but limited to word-deafness. The patient can hear ordinary sounds, though more or less badly, he can talk correctly, can write correctly, can read aloud, and understand what he reads. His three disabilities are that he is unable to comprehend spoken words, and that he is consequently unable either to repeat words or to write from dictation.

I cannot agree with the pathology of the affection as given by Lichtheim or with that advanced by Déjerine. Lichtheim says": "Both ears are capable of receiving and transmitting excitations of speech, but intelligence of language is bound up with the activity of the left hemisphere only, so both acoustic nerves must enter into relation with the latter." Thus the affection we are considering, he adds, "can obviously come into existence only if the irradiations of both acoustic nerves in the left temporal region are broken through." He concludes that the union of these two tracts takes place in the cerebral hemisphere above the level of the

38 Journal of Physiology, 1889, p. 429.

39 Natural History Review, vol. i., p. 296.

" Brain, January, 1885, p. 460. 
internal capsule, and he believes it to occur somewhere in the white matter of the temporal lobe. A lesion in this situation, therefore, cutting off, as he assumes, the afferent fibres of both auditory nerves on their way to the left auditory word.centre, is the explanation that Lichtheim gives of the production of "isolated speech-deafness." Déjerine's view is still less satisfactory, as he speaks only of a severance of one set of afferent fibres proceeding to this centre. ${ }^{42}$

In regard to these explanations it may be said that the view of Déjerine is certainly insufficient, since, as I have already observed, it is well known that the cutting off of the afferent impressions going to the brain from the right ear alone does not give rise to word-deafness. Lichtheim's explanation, on the other hand, is unsupported by any anatomical facts showing the distribution that he assumes to exist, which would really be that of a semi-decussation of the auditory nerves, since, after speaking of his imaginary arrangement on the left side of the brain, he adds in a footnote, "a similar distribution must obtain in the right hemisphere." Both Lichtheim and Déjerine seem to think that the right auditory word-centre is either non-existent or possessed of no functional activity, and consequently that it is not brought into relation with the left auditory wordcentre. They seem also to hold similar views as to the absence of a visual word-centre in the right hemisphere. If these views were correct, surely such convolutional regions in the right hemisphere ought to show some distinct diminution in size and development as compared with those of the left side. But no one as yet seems to bave noticed anything of the sort.

There was no necropsy in Lichtheim's case of "isolated speech deafness," and from the particulars given it seems clear that the patient was generally rather deaf, altogether apart from his word-deafness. Thus my interpretation of this case some time since, after a careful study of its details, was that there probably existed pretty complete deafness on the right side, cutting off the left auditory word centre from its proper incitations, whilst the slight sudden brain attack that is recorded to have occurred in June, 1882, may in some way have destroyed the commissural fibres connecting the left with the right auditory word.centre. In this way we should have the isolation of the left auditory word-centre brought about without the necessity for postulating the existence of any hypothetical and altogether unproved distribution of the auditory fibres within the brain. We should, in fact, have to do with a man partially deaf, capable of hearing noises only, but not able to perceive the meaning of spoken words-owing, on the one hand, to the complete isolation of the left auditory word-centre from all sounds; and, on the other, to the inadequacy for this purpose of the right centre alone, because of the imperfect development of associational fibres in connexion with speech functions in this hemisphere. This view has since been rather confirmed by the record of another case by Sérieux, ${ }^{43}$ in which it is definitedly stated that the patient was absolutely deaf on the right side, as a sequence of an old otitis. The following are a few brief details concerning this case.

CASE 31.-The patient was a woman, aged fifty-one years. She had been suffering from partial word-deafness for six years. There was a complete absence of word-blindness, of motor aphasia, and of agraphia. Her hearing was normal on the left side, but absent on the right by reason of an old otitis. There was musical amnesia, the patient being unable to recognise or to sing certain airs. There was ineomplete worddeafness; and writing from dictation was defective. There was slight paraplasia and paragraphia in spontaneous speech and writing. Comparaphion and pritten pia in spontant prehension of written language was slightly affected. There was progressive dovelownent of sympoto sing cer pow at ock and the pow of writio from dictation was lost. Her spontaneous poech and witing sul

Strangely enough it has been found that a very similar clinical combination may be produced in quite a different way, as may be seen by reference to the very remarkable case, previously cited from Pick, of destruction of the auditory word-centre in each hemisphere. Here the clinical condition was almost identically the same. There was even a certain amount of general deafness, though it was not due to middleear disease, nor did it seem to be definitely localised to one side. As I have already said, this case seems absolutely inexplicable unless we are to suppose that the patient was a "visual" who could speak, write, read aloud, and understand

42 Mémoires de Ja Société de Biologie, 1891, p. 112.

43 Rerue de Médecine, 1893, p. 733. It is quoted also by Mirallie (loc. cit, p. 190). wha he read, mainly through the activity of the visual and the kinæsthetic word-centres-at all events without the coöperation of the auditory word-centres, seeing that these were destroyed. The case shows, moreover, that general deafness does not result from destruction of these special word-centres even in both hemispheres. The patient's general hearing power was defective, though far from lost.

These are the only three cases of "isolated word-deafness" known to me.44 It will be seen from what I have said that this rare group of symptoms is capable of being induced in two very different modes-just as we shall find subsequently that what Déjerine has called "pure word-blindness" may also be produced in two different modes, and that the modes are analogous in the two cases. Pick was fully aware of the very unusual nature of his case. He recognised that it could not be a case of sub-cortical word-deafness of Lichtheim's and Déjerine's type, though he was not prepared to advance any other interpretation. Mirallié, however, has been so very uncritical as to cite it ${ }^{45}$ as an example of Déjerine's type, notwithstanding the fact of the existence of the double cortical lesions occupying the sites of the auditory word-centres.

( $T_{0}$ be continued.)

TWO CASES OF

\section{INTUSSUSCEPTION SUCCESSFULLY TREATED BY LAPAROTOMY; ONE PRESENTING SEVERAL} UNUSUAL FEATURES.

\section{BY R. LAWHORD KNAGGS, M.C. CANTAB.,} F.RC.S. ENG.,

ASSISTANT SURGEON TO THE LEEDS GETERAI INEIRMARY.

OF the following cases the first is of special interest, more from the suggestive nature of some of the symptoms than from the numerous risks which the little patient successfully surmounted.

C.LSE 1.-A girl, aged eight years, the subject of a perfectly controlled right inguinal hernia, was admitted into the Leeds Infirmary under Mr. Mayo Robson on Aug. 7th, 1896, and in his absence came under my care. Serenteen days before, when at school, she was seized with pain in the abdomen during defecation. From that time vomiting had been constant and pain intermittent. Actions of the bowels were obtained on the sixth and eleventh days, and the motions contained neither blood nor mucus. Though flatus was passed occasionally, the abdominal distension had gradually increased. Two days before admission all her symptoms were aggravated and the obstruction became apparently complete. When first seen on the evening of Aug. 7th there was great abdominal distension and general tympanites. Vigorous visible intestinal movements could easily be excited, but no tumour could be felt. The tongue was moist and furred, the pulse was 140 , and the intelligence was clear. The condition to be dealt with was obstruction, not strangulation, and the patient's condition was critical; so enterotomy, to tide her over the immediate danger, was decided upon in case there was any difficulty in finding the cause of the trouble. On opening the abdomen in the middle line the distension produced by the enlarged small intestine was so tight that the utmost difficulty was experienced in insinuating the fingers between it and the parietes to explore the hernial orifices and the cæcal region. Nothing suspicious was detected, and to have done more some of the coils of bowel must have been brought outside the abdomen, a proceeding which I feared would be likely to add very greatly to the severity of the operation. A knuckle of small intestine was therefore selected and fastened in the lower angle of the wound, which was then closed. The bowel was opened at once and a Paul's tube inserted. The operation did not take long, and the patient stood it well. Perfect relief was obtained, and the patient's general condition quickly improved, but she remained subject to spasms of pain-less severe, certainly, than before, but sufficient to wake her during sleep and to call for the administration of opium at times. When the distension had completely

$4 \pm$ Though Wernicke says a few words concerning a case that had come under his observation (see Fortschritte der Medicin, 1886, p. 474). 